\title{
The Graduate Specialization in EngineERING EdUCATION
}

\author{
Jillian Seniuk Cicek ${ }^{1}$, Marcia Friesen ${ }^{2}$, Danny Mann ${ }^{3}$, Nishant Balakrishnan ${ }^{3}$, Renato Bezerra Rodrigues ${ }^{3}$, and \\ Jeff Paul \\ Centre for Engineering Professional Practice \& Engineering Education ${ }^{1}$, Dean's Office in the Price Faculty of Engineering ${ }^{2}$, \\ Department of Biosystems Engineering ${ }^{3}$, University of Manitoba \\ Jillian.SeniukCicek@umanitoba.ca
}

\begin{abstract}
There has been substantial growth in the formal focus on the pedagogy of engineering in the last two decades. Formalized pathways in Engineering Education (Eng.Ed), including Master's and Ph.D. degree programs and university departments, have been established in several prestigious universities globally, with many founded in the U.S.. Interest in Eng.Ed in Canada has also grown, but up until very recently there has only been one formal pathway for graduate research in this field. In Fall 2020, the Department of Biosystems Engineering at the University of Manitoba welcomed the first three doctoral students into the Graduate Specialization in Eng.Ed (GSEE). In this paper we discuss the motivations for, and objectives and benefits of the GSEE, and describe its development. We share challenges encountered, and opportunities envisioned, and the intentions and motivations of the three graduate students who chose this pathway. We reflect on the importance of Eng.Ed programs for the advancement of engineering education research and the development of the discipline in Canada. Descriptions of our efforts and challenges are intended to help the development of additional Eng.Ed specializations or graduate programs in Canada.
\end{abstract}

Keywords: graduate students; institutional change; engineering education; Canada; advancement of a field; scholarly dialogue

\section{INTRODUCTION}

Major shifts are occurring in the teaching and practice of engineering [1]. Global crises and competition are increasing the need for technological innovations that will support societal and national prosperity [2-4]. The quest to address complex societal needs is broadening the scope of engineering to include knowledge and skills in design, teamwork, leadership, multicultural and interdisciplinary aptitudes, communication, lifelong learning, business, and dispositions for sustainability, globalization, innovation, and entrepreneurship [5]. A diverse engineering workforce is required, skilled in critical thinking, problem-solving, communication, and innovation [6-8]. Research in Engineering Education (Eng. Ed) is critical to address multiple national priorities, including increasing the productivity, innovation, and competitiveness in Canada in multicultural, sustainable, and responsible ways and generating opportunities for diverse, underrepresented groups [9]. These transformations are expanding the competencies necessary for engineers today, requiring the development of innovative engineering curricula to assist engineering students in cultivating and making full productive use of their diverse technical and professional strengths [10-15].

As such, there has been a substantial growth in the formal focus on the pedagogy of engineering in the last two decades [16]. Formalized pathways in Engineering Education, including Master's and Ph.D. graduate degree programs and university departments, have been established in several prestigious universities globally [17-19]. In fact, as of 2020 there were 52 institutions offering engineering/STEM education graduate programs globally [20], most founded in the U.S.

Interest in Eng.Ed in Canada has also grown, although more slowly, indicated by the expansion of the Canadian Eng.Ed Association (CEEA-ACEG), increasing annual attendance at its national conference, and the number of graduate students conducting engineering education research (EER) [21]. At the University of Manitoba (UofM), engagement in Eng.Ed has also advanced. Many influences increased this focus, including internal motivations of individual professors exploring innovative classroom methods, and external stimuli such as changing accreditation requirements. Critical to this development has been the championing of Eng.Ed. by three NSERC Chairs in Design Engineering spanning five terms, and culminating in the formation of the Centre for Engineering Professional Practice and Eng.Ed (The Centre). All told, there is work being done to position Eng.Ed as a component of scholarship and research at the UofM.

Despite these advancement locally and nationally, the growth of the field of Eng.Ed in Canada is arguably constrained. This is demonstrated by the low number of Canadian EER journal publications [22-25], lack of dedicated funding [26] and faculty appointments specific to EER [18], and dearth of formal program options available for graduate students [21][26]. For example, although there has been a growing number of graduate students at the UofM and other institutions across Canada conducting Eng.Ed research, up until very recently, there has only been one pathway for formally acknowledging graduate research in this field [27] at the University of Toronto [28]. Over the last decade, the UofM has graduated six students who completed degrees with Eng.Ed foci; but these students were accommodated through traditional engineering or interdisciplinary programs. Unfortunately, these avenues do 
not lead to formal recognition of their Eng.Ed specialization. Additionally, the institutional structures in place for engineering or interdisciplinary degrees do not always readily support Eng.Ed graduate students [21][26]. Developing as a researcher in Eng.Ed via these nondedicated pathways is often left to students' agency. Findings from a recent study on the identity of graduate students studying Eng.Ed in Canada indicate that these students experienced the absence of a community of practice (CoP), doubted the legitimacy of Eng.Ed as a 'real' discipline/field, and struggled with an academic identity crisis [27]. The authors argued that the development of Eng.Ed CoP with their sociocultural supports at individual institutions in Canada will benefit Eng.Ed graduate students, and in turn, develop the field.

The newly established Graduate Specialization in Engineering Education (GSEE) at the UofM addresses this need. It has been five years since faculty reported on the development of an Eng.Ed program at the UofM [29]. That work has finally been completed, and in Fall 2020, the Department of Biosystems Engineering (BIOE) welcomed the first three GSEE Ph.D. students. The GSEE provides an avenue for formal recognition of graduate student scholarship and research in the burgeoning global discipline of Eng.Ed [30-32]. It follows the lead of the U.S. in particular, which has to date established several stand-alone Eng.Ed graduate degree programs [20] buoyed by significant, longstanding national funding [33]. Recognizing the interdisciplinary nature of the field of Eng.Ed, the GSEE was developed in collaboration with the Price Faculty of Engineering and the Faculty of Education, and will be authentically supported by the collaboration of both engineering and education experts, and the development of an authentic CoP [34][35]. The goal of this collaboration is to work together to explore and develop research methods and pedagogical practices that are authentic to Eng.Ed .

The purpose of this paper is to describe the GSEE, celebrate its development and the efforts of its champions, and reflect on why Eng.Ed programs are important for the advancement of EER and the development of the discipline in Canada. We discuss: the motivations for, and objectives and benefits of the GSEE; its development and requirements; similar programs/pathways in Canada; challenges encountered; and opportunities envisioned. We share, and reflect on the intentions and motivations of the three graduate students who have chosen this pathway. Descriptions of our efforts and challenges are intended to help the development of additional Eng.Ed specializations or graduate programs in Canada, and stimulate reflection on the impact of Canadian Eng.Ed advancements globally.

\section{MOTIVATIONS, OBJECTIVES \& BENEFITS}

The program is intended to attract highly qualified students from across Canada and the U.S., as to date, only one other similar option exists in Canada (i.e., the
Collaborative Specialization in Eng.Ed at the University of Toronto [28]); other formal options are much more expensive degree programs in U.S. schools. Prospective students are expected to include engineering or education graduates or practicing engineers who wish to pursue an academic career in the discipline of Eng.Ed and currently lack Canadian options to do so; or who desire a more comprehensive knowledge and skill set for professional roles in private, public, and not-for-profit sectors.

In the larger landscape, the GSEE will support the continual evolution of Eng.Ed and facilitate culturally specific content and evidence-based delivery [36]. Specifically, it will provide an avenue for engineering educators to engage in the theoretical foundation of engineering teaching and learning, and to develop an active research field in Eng.Ed in the Canadian context to address uniquely Canadian needs. It is also envisioned to provide an avenue to support workplace training needs for workers in a shifting and high-tech economy through better-prepared workplace trainers and instructors. It will support college and university STEM faculty instructors in new educational paradigms and graduate a new generation of EER scholars.

\section{CONSULTATION \& DEVELOPMENT}

The program development took a number of years as various program options were explored and extensive discussions held with partnering Faculties and administrative units. Evolution can be traced from 2015 when the development of the program was first introduced at the CEEA-ACEG annual conference [29]. Two coordinators were appointed from the Price Faculty of Engineering and the Faculty of Education to recommend a course plan for a post-graduate degree program in Eng.Ed. The proposed program, conceived as a master's degree, was to be executed in five phases, beginning with a parallel, but independent, dual-entry process for students in the Faculties of Engineering and Education, followed by two sets of tributaries designed for students to participate in specialized courses. For example, Education entry students would engage in engineering-based courses focused on the design process and Eng.Ed at the K-12 levels, and the Engineering students would be introduced to an in-depth study of teaching and learning and Eng.Ed at the post-secondary level. Both entry streams would re-unite for collective courses in the middle and at the end of the program, with the program culminating in a capstone final project/thesis.

Through its course, faculty members responsible for the program's advancement changed. There were several iterations and attempts to have the program approved at department, faculty, and university/central/senate administration. It was determined that a graduate degree program in Eng.Ed was infeasible: The Province was not keen to expand the number of degree programs at Universities; new degree programs typically require additional funding, which was a barrier in this case; and we 
were unable to find a program structure that met the needs of both Engineering and Education faculties.

The objective of the Price Faculty of Engineering was to develop a graduate program for students interested in exploring engineering education as an academic discipline, for future careers in academia, post-secondary teaching in engineering and technology education, and careers as industry trainers. The Faculty of Education graduate students are typically K-12 educators who are developing additional expertise in a specific area as they continue their K-12 teaching careers. Education foresaw that a graduate program in engineering education may appeal to K-12 educators with an interest in improving and expanding K-12 STEM teaching and learning. Given that the graduate program in engineering would entail four courses (as per Faculty of Graduate Studies requirements, confirmed with Engineering departmental supplemental regulations), it was difficult to envision a program that would meaningfully facilitate all objectives for both faculties in a single, commensurate program structure. The issue was not so much a lack of collaboration between engineering and education, but rather incommensurability of the (critical mass of the) graduate students' career objectives across the two Faculties. These led to a new structure and the proposal of the GSEE.

The GSEE was presented to the four department councils in the Price Faculty of Engineering: Biosystems, Civil, Electrical and Computer, and Mechanical Engineering. The Department of Biosystems approved the GSEE as an option within their Ph.D. program in September 2019, and the University Senate approved the GSEE in June 2020. The first three students accepted into the program with the GSEE began in September 2020. The GSEE will enable graduate students to gain expertise in the field of Eng. Ed and formal recognition of that expertise. Although the GSEE is currently situated within only one engineering department, this is not anticipated to hinder student recruitment as students are not required to have Biosystems Engineering backgrounds to enrol in this program. This being said, the Department of Electrical and Computer Engineering has shown interest in the GSEE, and it is anticipated that more departments may adopt this specialization going forward.

\section{GSEE IN THE DEPARTMENT OF BIOE}

The GSEE is offered and administered by the Department of BIOE within its Ph.D. program. It builds upon existing courses in the Faculties of Education and Engineering, with the addition of two newly developed Eng.Ed courses (ENG 7030 The Discipline of Eng.Ed and ENG 7040 Foundations of Eng.Ed Research) to form a coherent concentration (approved by Senate in November 2019). The student's primary advisor must be a member of The Centre. A preparatory pathway for students with no prior academic work in Eng.Ed who wish to apply for the GSEE is available through the BIOE M.Eng. degree through a recommended set of courses and program advising. This preparatory pathway is accommodated within the present requirements of the M.Eng. program and did not require a formal proposal.

\subsection{GSEE Program Details}

The Ph.D. degree in BIOE with a GSEE requires 12 credit hours of 7000-level coursework and a research-based thesis in an Eng.Ed topic. Required courses are shown in Table 1. Other Department, Faculty, or University requirements (e.g. Academic Integrity Tutorial) are in addition to these requirements. The GSEE does not increase the degree requirements nor extend the time-to-completion.

Normally, applicants applying for admission into the $\mathrm{Ph} . \mathrm{D}$. program in the Department of BIOE are required to hold a M.Sc. degree in BIOE or equivalent from a recognized university. However, in consideration that applicants interested in the GSEE may not have this traditional engineering background, it was determined that applicants with degrees in related areas may be recommended for admission by the Department Head. A process has been established that involves the submission of a written statement explaining the motivation for applying to the GSEE, which is reviewed by the BIOE Graduate Studies Committee, and a recommendation forwarded to the Department Head. Ultimately, acceptance must be approved by the Faculty of Graduate Studies.

\section{Table 1 - GSSE required courses}

\section{BIOE7270 Advanced Seminar in BIOE Engineering \\ One of: Note: these have prerequisite EUDA5080/1 \\ EDUA7840 Qualitative Research Methods in Education \\ EDUA7850 Design \& Analysis of Educational Research (Quantitative) \\ Or equivalent Research Methodology Course}

Two of:

ENGG7010 The Engineering Design Process

ENGG7030 The Discipline of Eng.Ed

ENGG7040 Foundations of Eng.Ed GRAD8010 Graduate thesis with public defence focused on

\subsection{Similar Programs in Canada}

The University of Toronto ( $\mathrm{U}$ of $\mathrm{T}$ ) offers The Collaborative Specialization in Eng. Ed through the Faculties of Applied Science and Engineering and Education. This is a Post-Graduate Specialization in Eng.Ed in which an additional scope is added to a regular/existing engineering graduate program. The outcome is a transcript notation. The additional scope consists of a core course, a seminar series, and a thesis/project focused on Eng.Ed , and at the Ph.D. level, an additional elective course. The GSEE is similar to the program at the $\mathrm{U}$ of $\mathrm{T}$, but there are some 
differences: the $\mathrm{U}$ of $\mathrm{T}$ program is offered at both the master's and doctoral level, whereas the GSEE is offered at the doctoral level at the $\mathrm{U}$ of $\mathrm{M}$. The $\mathrm{U}$ of $\mathrm{T}$ also offers the CSEE in five departments across two faculties, supported by 20 professors, whereas the GSEE is only offered in one department thus far, supported by a few professors.

At Queens University, graduate students interested in Eng.Ed register in the engineering department based on their background or that of their advisor. The course list is adapted from a typical engineering graduate program by approval of the department chair and usually includes educational research courses from the Faculty of Education. The official degree is the traditional one (for example, M.Sc. in Civil Engineering) and as such, does not offer formal recognition of the student's Eng.Ed earned qualifications.

Presently, the University of Calgary - Schulich School of Engineering has submitted a proposal for a new degree program, entitled, Interdisciplinary Specialization in PostSecondary STEM Education, which will include research and scholarship in the discipline of Eng. Ed.

Significant funding has resulted in explicit pathways for EER graduate students in the USA. For details, see [27].

\section{CHALLENGES \& OPPORTUNTIES}

There were/are some challenges in conceptualizing the GSEE, in obtaining approval, and in executing the program:

- Program champions: The GSEE took five years to approve. In that time, faculty and administrators working on, and familiar with the proposal changed, which extended the time and effort required to get the GSEE approved.

- Program avenue: Originally the program was conceived as a new master's program, but due to Provincial restrictions, structural incompatibility between the Faculties of Engineering and Education, and financial barriers, this was infeasible. Through several conceptualizations (degree program, concentration, specialization) the specialization was the avenue chosen.

- Program level: When discussed by the members of the BIOE Department Council, there was opposition to the non-technical nature of the GSEE being offered through the M.Sc. program. This was due to the fact that Engineers Geoscientists Manitoba provides all M.Sc. students in engineering programs at the UofM with one year of professional experience credit towards registration as a professional engineer in Manitoba. There was concern that the introduction of a GSEE specialization at the master's level would cause Engineers Geoscientists Manitoba to revise this policy, negating the substantial time required to negotiate the automatic one year of credit, and creating incremental effort associated with assessing individual master's programs at the UofM. Thereby, the GSEE was re-envisioned and re-proposed for the $\mathrm{PhD}$ program. Members of BIOE Department Council acknowledged that there may be individuals interested in the GSEE not holding a master's degree; it was envisioned that such students could prepare for the GSEE at the PhD level by completing the existing course-based M.Eng. program.

- Program approval: The Price Faculty of Engineering offers five engineering programs: BIOE, Civil, Computer, Electrical, and Mechanical. Although other departments were interested in the GSEE, to date, is has only been approved by the Department of BIOE. It is expected that other Engineering departments will submit a similar proposal in the next few years. This, however, may not be a limitation or challenge for students necessarily. Students interested in the Ph.D. degree in BIOE with a GSEE may apply with degrees in related areas. To date, of the three GSEE students enrolled, one does not have an undergraduate engineering degree, but holds a M.Sc. in software engineering; another has an undergraduate Mechanical engineering degree, and a Master's in Philosophy; and the third has an undergraduate and M.Sc. in Mechanical engineering. Thus, although all three students have engineering backgrounds in some capacity, they do not all have both an undergraduate and graduate degree in engineering, nor backgrounds in BIOE. Students are free to research all disciplines of engineering within the Eng.Ed context in the GSEE. A potential limitation of having the GSEE approved in BIOE could be if an advisor who is affiliated with one of the other engineering programs wants to supervise a graduate student in Eng.Ed.

- Availability of Education courses: Thus far, it has proven to be difficult to find GSEE students space in research courses (introduction to research approaches; quantitative or qualitative research) in the Faculty of Education. No formal mechanisms have been put in place in the Faculty of Education to 'save space' for the GSEE students (as is done for Education students). It seems anecdotally, that Education faculty teaching these research courses are not aware of the GSEE program. Department of BIOE GSEE students have had to find other avenues for fulfilling their course requirements, including taking qualitative research courses offered in the Faculty of Nursing, and in the Natural Resources Institute. These courses have proven to be very helpful from the students' perspectives and have enabled the discovery of qualitative research courses that are providing GSEE students with solid foundations.

- The BIOE Seminar course: The BIOE Seminar course is one of the requirements for GSEE students. This course has been designed to prepare students for an academic career, which includes acquiring skills in academic and grant writing via technical engineering topics. The courses have been designed for students in technical engineering fields, with presumably the assumption that students taking these courses do not have experience in academic writing, and will be working in a technical field. It has been noted anecdotally that these assumptions cannot necessarily be 
made for GSEE students. Going forward, it is recommended that the BIOE seminar course be reviewed and restructured to meet the needs of future GSEE cohorts.

- Awareness of the GSEE in the Faculty of Education: In the Faculty of Education, a formal GSEE option is not published. However, if an Education student has interest, there is enough flexibility in Education program requirements to accommodate students by strategic selection of coursework. To date, there has been no official report of awareness or interest from the Faculty of Education. This lack of knowledge, and potential lack of traction in the Faculty of Education could be due to a change of Deans in both faculties, as well as the flux caused by the pandemic. Faculty members from Engineering met with the Department Head of Educational Administration, Foundations \& Psychology in April 2021 to discuss the GSEE program and the Faculty of Education's (lack of) awareness. Plans were made to discuss the GSEE with the incoming Dean of Education in Fall 2021.

- Eng. Ed faculty: The implementation of the GSEE is an important avenue specifically for non-engineering Eng.Ed faculty members to develop their research programs.

\section{INAUGURAL GSEE STUDENTS}

In September 2020, three $\mathrm{PhD}$ students enrolled in the inaugural GSEE in the Department of BIOE. All came for diverse reasons, from diverse backgrounds, and with diverse research interests. One is a mechanical engineer and instructor in the Price Faculty of Engineering who is interested in conducting quantitative research to validate peer assessment in teams. Another is a retired Military Officer with a physics degree, master's degrees in software engineering and in Public Administration, with 20 years' experience as an instructional designer. He is interested in using grounded theory and design-based research (DBR) to develop educational tools embedded with pedagogical content knowledge grounded in cognitive theory, neuroscience, and learning science to support effective STEM teaching and learning. The third student is a mechanical engineer from Brazil, with a Master's of Philosophy in Humanities from Canada, who will conduct qualitative research to examine socio-technical thinking in engineering. Here, they reflect on their intentions and motivations for enrolling in the GSEE. Sharing their reflections is intended to help the CEEA-ACEG community understand the importance of having formal pathways for graduate students in EER in Canada.

\subsection{Student 1 - Mechanical Engineer \& Instructor}

As a faculty member who is in a teaching stream position, my main motivations for entering a program of study in Engineering Education are centered around:

1. Gaining knowledge about research in Eng.Ed,
2. Creation of knowledge around engineering teaching and learning, and

3. Creating opportunities to explore research relevant to my teaching and learning interests.

Before entering the program, I would have generally classified myself as a "hobbyist" in Eng.Ed - someone with a keen interest in the subject but who has only explored it in a casual manner. When I saw the option to do a program in it (and notably a specialization that has coursework dedicated to Eng.Ed instead of just educational research), I saw that as an opportunity to build my own knowledge, skills, and capacity for research. This comes from not only the coursework and research focus, but from also building a community of practice with other individuals who are interested in the field, and to (as is often the case with social science research) engage with others to learn about other epistemologies and ontologies that exist to help shape my own. This provides me with strong support for motivation 1 and builds my capacity to embark on rigorous Eng.Ed research.

As an educator myself, I find that we (collectively) try to innovate, develop, and foster knowledge as best as we can, but there is a genuine lack of knowledge in many cases of the ways in which students engage with engineering and how it affects their ways of knowing, thinking, and being. These gaps are what I find as the key areas that I personally want to focus my own research on. The main motivation for specifically looking at doing graduate work in this field is to help develop my capacity to develop and ultimately create/share knowledge in the field. This provides me with strong support for motivation 2 and gives me capacity to collaboratively work with others to expand our collective knowledge as engineering educators through the field of EER.

As a faculty member who chose to take up a teaching stream position, my interests and motivations clearly lie in the ability to teach students and share knowledge, but with a position where the role is centrally focused on teaching and service, research is not normally a central focus. EER is however a field that easily works into my own role well and provides me with an opportunity to explore aspects that are interesting to me (engineering identity, student learning, ways of thinking) that also directly align with my own teaching interests. This provides me with motivation 3, where a future in EER research is something that not only aligns well with my interests, but also my own career development goals.

\subsection{Student 2 - Retired Military Officer \& Educational Designer}

I would divide my rationale for choosing the Engineering Education Research (EER) curriculum into several core ideas: some personal, some expediency, and some selfish.

First, I consider myself a life-long learner. I love learning, and specifically, learning in the academic environment. As 
well, I have found that my pathway of working in the field (i.e., software, bureaucracy, education) and then following it up with a degree in the related field has been intriguing. Learning the theories after I have learned in the trenches has provided me with many epiphanies. I'm not sure that if had I learned the theories first that they would have resonated as strongly with me. Given how well this worked in software and administration, I wanted to do the same with education.

Thus, having worked for over 20 years in education, I wanted to learn the theories behind education. For adults. In a professional setting. Unfortunately, as I was to discover, this is not a focus of research in most education departments, which tend to focus on areas such as $K-12$, education leadership and social issues. I wanted to focus on how the brain works (in adults) in order for learning to occur. I consider myself an effective instructor but did not know WHY. I felt that in order to share my practical knowledge, I had to learn the theories underpinning learning.

Though I had contacts in academia and education, I discovered the GSEE program by accident through a family connection. It fit my desires much better than any of the other programs I had investigated. It focused on the education of adult professionals. OK, so I'm not an engineer, but I have taught and worked with engineers for most of my career, so I was excited to begin this next phase of my life. And, part of me hopes that I can find a way to help make instructors effective without requiring them to spend 20 years in the classroom to learn their craft.

This leads to my selfish reasons for choosing EER. First, our family was settled in Winnipeg, and I needed to find a program in Winnipeg. I wasn't prepared to move, nor did I want an online program (I know, there is a little irony there given the pandemic). Second, it is my belief that one of the ways to stay sharp as we age is to continue to learn and challenge yourself. I wanted to go back to school to stay sharp. My self-identity is entwined with my intellect. Anything I can do to maintain my intellect is important.

Lastly, as I look towards the next phase of my life, I'm hoping to continue to instruct (sessional) courses at the university level, and that generally requires a PhD. Teaching will keep me involved in academia and staying sharp. Plus, the sessional pay, though not much, would be a nice supplement to my retirement income.

And that is how I landed in an EER program.

\subsection{Student 3 - Mechanical Engineer from Brazil with Master's in Philosophy}

After I finished my undergrad (mechanical engineering), I was feeling "incomplete." That is because I was sold that engineering was about using scientific knowledge to develop technologies for the benefit of society, when, in fact, I learned only until “... to develop technologies;" the "for the benefit of society" was left aside.

Also, I was unsure about my future and what career I wanted to follow - even though I had a job offer to work in a car factory. I wanted something that I felt was meaningful, more noble and that I could help other people more directly. But would that mean that I had to go back to university again and do another undergraduate degree? And that's when it hit me: "I want to be a professor/teacher!" (in Portuguese it's the same word). In the meantime, I started teaching English and some engineering courses as a private tutor. It was amazing! Then, driven by my feeling of incompleteness and my "calling," I started a master's degree in humanities (technology and society) to explore what meant to work "for the benefit of society" as an engineer. Crossing this boundary was a shock at first and it was like I was incapable of learning those new things. After two years of training, I finished the degree and felt like my way of thinking had gone through a massive renovation. I felt complete as an engineer.

I believed that engineering students should have this "eye-opening" experience as well, but without having to go through a masters in other discipline. So, following my "calling," I started looking for opportunities to continue my studies and start a PhD in which I could conduct research on Eng.Ed. At the time I started searching, there was only one program in Canada (UofT), but many others in the U.S. And, since I wanted to stay in Canada, I was willing to "improvise" my degree as many students that I had talked to - you are housed in a traditional engineering discipline but allowed to research Eng.Ed. I knew that coursework would be a struggle, but there weren't many options. After extensive searching for potential supervisors - "cold emailing" and going to the CEEA-ACEG conference with this sole interest - I was down to two professors. I applied and was accepted at both universities.

Some factors influenced my decision to come to the University of Manitoba: the size and affordability of the city, employability for my wife, and, of course, the PhD program itself. Soon after I was accepted, the GSEE program was formalized and it was a huge factor in my decision. Knowing that I would have a program with the proper (and formal) structure, courses, processes, and recognition of having a specialization in Eng.Ed was crucial for my decision. Also, the idea of having a "house," a community and a formal identity within UofM was important for me. I didn't want to feel like a fish out of water.

So, I came to UofM and I am pretty happy and satisfied with my experience so far.

\section{REFLECTIONS \& TAKE AWAYS}

Reading these three students' intentions and motivations for choosing and enrolling in the GSEE is poignant and very satisfying. The program has met the diverse needs of three diverse students. They have brought their love for learning, their enthusiasm and passion for Eng.Ed, and their incredibly 
diverse and highly developed knowledges and skills to this program, and have ignited the Eng.Ed community at the UofM. Two of the authors on this paper were what we consider 'first gen' Eng.Ed students - students who conducted Eng.Ed research through traditional engineering or interdisciplinary routes. It is clear to us, comparatively, the difference between not having and having a formalized pathway for Eng.Ed and a critical mass for an institutional Eng.Ed community. Presently, in our Eng.Ed CoP at the UofM we have three GSEE students and six master's level students, and several faculty members. The value of having a formal pathway and a COP within one's own institution is already evident in the research conversations being had on ontologies and epistemologies, the identity of the field, and theoretical frameworks and methodologies. It is apparent in the EER projects these students have undertaken above and beyond the valuable Eng.Ed doctoral research they are proposing to conduct. These emergent projects include the content analysis of the CHEER-UP recordings (ASEE 2021); the content analysis of the CEEA-ACEG proceedings to identify the Canadian Eng.Ed research agenda (CEEAACEG 2021 paper \#33); pair coding as a qualitative method for consensus building (FIE 2021); and the quantitative validation of the UofM SRI (Student Rating of Instruction) tool. The research on graduate student identity and $\mathrm{CoP}$, and the rapid development of formal Eng.Ed degree programs and communities and the vast and rapid dissemination of Eng.Ed research specifically in the U.S., points to the value of $\mathrm{CoP}$ for the development and establishment of Eng.Ed as a discipline. We argue that our formal efforts in the Department of BIOE at the UofM to advance Eng.Ed research via the GSEE will support the growth of the field in Canada, and the presence and impact of Canadian Eng. Ed researchers globally.

This being said, there are some take-aways that may help others in developing formalized programs in engineering education. One hurdle that took time to undo was that Engineering came up with a program structure and presented it to Education, with willingness to tweak. Ultimately this did not work. A joint program would need to bring both/all Faculties to the table at the outset before any program structure is conceptualized to determine respective objectives, joint interests, and the potential audience for a graduate program in engineering education.

Faculty and University culture are really important in developing joint graduate programs in terms of senior administration's overall interest in or appetite for such programs, and the models available within institutional policy structure. This will vary by institution, but getting a sense of what the University (e.g., Faculty of Graduate Studies, Provost's Office, Senate) will support at the outset can save a lot of time.

If an institution has students who are achieving their engineering education graduate program goals in nontraditional ways, a helpful approach can be to look at what is already happening through creative and non-traditional ways (e.g., often open-minded department and advisors), and developing a pathway that gives formal recognition to these activities. It is a bit like the concept of a desire path. No matter where the City builds a sidewalk, pedestrians will walk the desire path if it is shorter, safer, and more convenient. Paving the desire path is likely a better and more efficient approach than building a new, potentially undesirable path that may require all kinds of fencing, other structures and permissions, invariably taking more time.

\section{CONCLUSION}

The engineering education landscape within Canada continues to evolve. Several developments in the last few years, including the growth of CEEA-ACEG, the changing CEAB accreditation requirements, and global influences particularly in America have spurred a growing interest among Canadian academics. The Department of Biosystems Engineering at the University of Manitoba is capitalizing on these trends and has developed the Graduate Specialization in Engineering Education (GSEE). This formal avenue for graduate research in engineering education will benefit graduate students who are interested in studying in the field, as well as Canadian engineering educators and researchers. It will support the growth of engineering education in Canada, and the presence and impact of Canadian engineering education researchers globally.

\section{Acknowledgements}

We are grateful to Dr. Sandra Ingram, Dr. Richard Hector, Dr. David Mandzuk, and the late Dr. Douglas Ruth, who began, and were an integral part of the development of the GSEE. Thank you to the CEEA-ACEG reviewers for your helpful feedback. We did not require ethics approval for this work.

\section{References}

[1] D. E. Goldberg, and M. Summerville, A Whole New Engineer: The Coming Revolution in Eng.Ed . Michigan: ThreeJoy, 2014.

[2] A. Jamison, "Turning engineering green: sustainable development and engineering education," in Christensen, S.H., et al (eds.). Engineering, Development and Philosophy: American, Chinese, and European Perspectives. Springer, 2012.

[3] W. Kastenberg, G. Hauser-Kastenberg, and D. Norris, "An approach to undergraduate engineering education for the 21st century," in Proc. Frontiers in Education (FIE) 36th Annual Conference, 5 pp., 2006. https://doi.org/10.1109/FIE.2006.322502

[4] W. P. Blair McDonald, and Nicholas Winowich, "Integrated engineering: An Engineering degree for the next generations work environment," in Proc. American Society for Engineering Education (ASEE) Annual Conference, (Honolulu, Hawaii), 2007.

[5] W. Sunthonkanokpong, "Future global visions of engineering education." in Proc. International Science, Social-Science, Engineering and Energy Conference 2010: Engineering Science and Management, 5 pp., 2011. Science Direct: Elsevier. doi: 10.1016/j.proeng.2011.03.029.

[6] J. G. Harris, E. M. DeLoatch, W. R. Grogan, I. C. Peden, and J. R. Whinnery, "Journal of engineering education round table: Reflections 
on the Grinter report," Journal of Engineering Education, vol. 83, no. 1, pp. 69-94, 1994. https://doi.org/10.1002/j.21689830.1994.tb00120.x

[7] Educating the Engineer of 2020. Washington, D.C.: National Academies Press, 2005. https://doi.org/10.17226/11338

[8] The Engineer of 2020. Washington, D.C.: National Academies Press, 2004. https://doi.org/10.17226/10999

[9] B. Frank, and G. Evans, Proposal for Letter from NCDEAS/CEEAACEG/Engineers Canada to NSERC/SSHRC: Call for National Funding for Engineering and Science Research, 2018.

[10]M. Henri, M. D. Johnson, and B. Nepal, “A review of competencybased learning: Tools, assessments, and recommendations," Journal of Engineering Education, vol. 106, no. 4, pp. 607-638, 2017. https://doi.org/10.1002/jee.20180

[11]C. Diduch, D. Macisaac, K. Haralampides, and B. Wilson, "Engineering and social justice through an accreditation lens: Expectations and learning opportunities for ethics and equity," in Proc. CEEA Canadian Engineering Education Conf., CEEC12, (Wpg., MB ; 17-20 June 2012) 5 pp., 2012. https://doi.org/10.24908/pceea.v0i0.4658

[12] J. Donald, S. Lachapelle, J. McIsaac, T. Abraham, R. Clemmer, K. Gordon, S. McCook, and R. G. Zytner, "Training versatile engineers: A historical and present perspective on the place of the humanities and social sciences in the Canadian engineering context," in Proc. CEEA Canadian Engineering Education Conf., CEEC15, (Hamilton, ON; 31 May - $\quad 3$ June 2015) 8 pp., 2015. https://doi.org/10.24908/pceea.v0i0.5797

[13] J. Donald, J., S. Lachapelle, T. Sasso, K. Augusto, and M. G. GonzalezMorales, M. G. (2017). "Why does it matter? Explaining the importance of complementary studies to first-year engineering students," in Proc. CEEA Canadian Engineering Education Conf., CEEC15, (Halifax, NS 19-22 June 2016) 6 pp., 2016 https://doi.org/10.24908/pceea.v0i0.6474

[14]H. Ebrahimi Nejad, "A systematized literature review: Defining and developing engineering competencies," in Proc. American Society for Engineering Education (ASEE) Annual Conference, (Columbus, OH; 24-28 June), 12 pp., 2017. https://doi.org/10.18260/1-2--27526

[15]C. Henderson, et al., "Towards the STEM DBER alliance: Why we need a discipline-based STEM education research community," International Journal of STEM Education, vol. 4, no.14, pp. $1-4$, 2017. DOI 10.1186/s40594-017-0076-1

[16]Jeffrey E. Froyd, and Jack Lohmann, "Chronological and ontological development of Eng.Ed as a field of scientific inquiry," in Cambridge Handbook of Eng.Ed Research. New York, NY: Cambridge University Press, 2014, 763 pp

[17] Aditya Johri, and Barbara M. Olds, "Introduction," in Cambridge Handbook of Eng.Ed Research. New York, NY: Cambridge University Press, 2014, 763 pp.

[18] Maura Borrego, and Jonte Bernhard, "The emergence of engineering education research as an internationally connected field of inquiry," Journal of Engineering Education, vol. 100, no. 1, pp. 14-47, 2001. doi: 10.1002/j.2168-9830.2011.tb00003.x.

[19]Phillip C. Wankat, "Analysis of the first ten years of the Journal of Engineering Education ," Journal of Engineering Education, vol. 93, no. 7, pp.13-21, 2004

[20]Adam Carberry and Ken Yasuhara, "Engineering Education Departments and Programs (Graduate)," Engineering Education List, PBworks. Available as of January 6, 2021 from http://engineeringeducationlist.pbworks.com/w/page/27610307/Engin eering $\% 20$ Education $\% 20$ Departments $\% 20$ and $\% 20$ Programs $\% 20$.

[21] Patricia Sheridan, Jillian Seniuk Cicek, Liz Kuley, and Robin Paul, "Characterizing the engineering education graduate student experience in Canada: Descriptives," in Proc. Canadian Engineering Education Association Conference, (Toronto, ON; 4-7 June), 7 pp., 2017.

[22]B. Williams, P. C. Wankat, "The global interconnectedness of engineering education research," Journal of Engineering Education, vol. 105 , no. 4 , pp. 533-539, 2016.

[23]P. C. Wankat, B. Williams, and P. Neto, "Engineering education research in European Journal of Eng.Ed and Journal of Eng.Ed : Citation and reference discipline analysis," European Journal of Engineering Education, vol. 39, no. 1, pp. 7-17, 2014. doi:10.1080/03043797.2013.867316

[24]B. Williams, P. C. Wankat, P. Neto, and C. Tiago, "Is engineering education research global? The answer may surprise you," in Proc. American Society for Engineering Education (ASEE) Annual Conference, (Indianapolis, IN.; 15-18June), 2014.

[25]P. C. Wankat, "Analysis of the first ten years of the Journal of Engineering Education," Journal of Engineering Education vol. 93, no. 1, pp. 13-21, 2004. doi: 10.1002/j.2168-9830.2004.tb00784.x.

[26] Jillian Seniuk Cicek, Patricia Sheridan, Liz Kuley, and Robin Paul, "Through 'collaborative autoethnography': Researchers explore their role as participants in characterizing the identities of engineering education graduate students in Canada," in Proc. American Society for Engineering Education (ASEE) Annual Conference, (Columbus, OH; 24-28 June), 10 pp., 2017.

[27] Jillian Seniuk Cicek, Robyn Paul, Patricia K. Sheridan, and Liz Kuley, "Researchers explore their roles as participant-researchers in characterizing the lived experiences of graduate students in engineering education research in Canada: A collaborative autoethnography," Canadian Journal of Science, Mathematics and Technology Education, 18 pp., 2020. DOI 10.1007/s42330-019-00075-5.

[28] "Collaborative Program in Engineering Education (EngEd)," University of Toronto, Faculty of Applied Science and Engineering, Engineering Graduate Studies. Available as of January 6, 2021 from http://gradstudies.engineering.utoronto.ca/researchdegrees/collaborative-program-engineering-education/.

[29] Sandra Ingram, Richard Hechter, Jillian Seniuk Cicek, and Douglas Ruth, "Pathways between engineering and education faculties: Efforts to establish an engineering education graduate program at the University of Manitoba," in Proc. CEEA-ACEG Canadian Engineering Conf., CEEC15, (Hamilton, ON; 31-3 May - June), pp. 6, 2015.

[30]"The research agenda for the new discipline of engineering education," Journal of Engineering Education, vol. 95, no. 4, pp. 259-261, 2006.

[31] Norman F. Fortenberry, "An extensive agenda for engineering education research," Journal of Engineering Education, vol. 95, no. 1, pp. 3-5, 2006.

[32] Brent Jesiek, Wendy Newswander, and Maura Borrego, "Engineering education research: Discipline, community or field?" Journal of Engineering Education vol. 98, no. 1, pp. 39-52, 2009. doi: 10.1002/j.2168-9830.2009.tb01004.x.

[33] Maura Borrego, and Barbara Olds, "Analysis of trends in United States National Science Foundation funding for engineering education: 19902010," in Proc. Research in Engineering Education Symposium, (Madrid, Spain, October), 2011.

[34] J. Lave, and E. Wenger, Situated learning: Legitimate peripheral participation. New York, NY: Cambridge University Press, 1991.

[35] Aditya Johri, and Barbara M. Olds, "Situated engineering learning: Bridging Eng.Ed research and the learning sciences," Journal of Engineering Education, vol. 100, no. 1, pp. 151-185, 2011.

[36] Gordon Monday Bubou, Ibebietei Temple Offor, and Abubakar Saddiq Bappa, "Why research-informed teaching in Eng.Ed ? A review of the evidence," European Journal of Engineering Education, vol. 42, no. 3, pp. 323-335, 2017. DOI: 10.1080/03043797.2016.1158793 